\title{
Characteristics and Clinical Course of Fusiform Middle Cerebral Artery Aneurysms According to Location, Size, and Configuration
}

\author{
Dongwook Seo, 'Si Un Lee, Chang Wan Oh, ${ }^{1}$ O-Ki Kwon, ${ }^{1}$ Seung Pil Ban, ${ }^{1}$ Tackeun Kim, ${ }^{1}$ Hyoung Soo Byoun, ${ }^{2}$ Young Deok Kim, \\ Yongjae Lee, ${ }^{1}$ Yu Deok Won, Jae Seung Bang ${ }^{1}$ \\ Department of Neurosurgery,' Seoul National University Bundang Hospital, Seoul National University College of Medicine, Seongnam, Korea \\ Department of Neurosurgery, ${ }^{2}$ Chungnam National University Hospital, Daejeon, Korea
}

Objective : To analyze the angiographic features and clinical course, including treatment outcomes and the natural course, of fusiform middle cerebral artery aneurysms (FMCAAs) according to their location, size, and configuration.

Methods : We reviewed the literature on adult cases of FMCAAs published from 1980 to 2018; from 25 papers, 112 FMCAA cases, for which the location, size, and configuration could be identified, were included in this study. Additionally, 33 FMCAA cases in our hospital were included, from which 16 were assigned to the observation group. Thus, a total of 145 adult FMCAA cases were included. We classified the FMCAAs according to their location (I-type 1, beginning from prebifurcation; I-type 2, beginning from bifurcation; I-type 3, beginning from postbifurcation), size (small, $<10 \mathrm{~mm}$; large, $\geq 10 \mathrm{~mm}$; giant, $\geq 25 \mathrm{~mm}$ ), and configuration (c-type 1, classic dissecting aneurysm; c-type 2, segmental ectasia; c-type 3, dolichoectatic dissecting aneurysm).

Results : The c-type 3 was more commonly diagnosed with ischemic symptoms (31.8\%) than hemorrhage (13.6\%), while $40.9 \%$ were found accidentally. In contrast, c-type 2 was more commonly diagnosed with hemorrhagic symptoms (14.9\%) than ischemic symptoms (10.6\%), and $72.3 \%$ were accidentally discovered. According to location, ischemic symptoms and hemorrhage were the most frequent symptoms in l-type 1 (28.6\%) and I-type 3 (34.6\%), respectively. Most of I-type 2 FMCAAs were found incidentally (68.4\%). Based on the size of FMCAAs, only $11.1 \%$ of small aneurysms were found to be hemorrhagic, while $18.9 \%$ and $26.0 \%$ of large and giant aneurysms were hemorrhagic, respectively. Although four aneurysms of the 16 FMCAAs in the observation group increased in size and one aneurysm decreased in size during the observation period, no rupture was seen in any case and there were no significant predictors of aneurysm enlargement. Of 104 FMCAAs treated, 14 cases (13.5\%) were aggravated than before surgery and all the aggravated cases were l-type 1.

Conclusion : While ischemic symptoms occurred more frequently in l-type 1 and c-type 3, hemorrhagic rather than ischemic symptoms occurred more frequently in I-type 3 and c-type 2. In case of I-type 1 FMCAAs, more caution is required in determining the treatment due to the relatively high complication rate.

Key Words : Aneurysm, Dissecting · Fusiform aneurysm · Middle cerebral artery · Natural history.

- Received : June 4, $2019 \bullet$ Revised : July 12, $2019 \bullet$ Accepted : July 26, 2019

- Address for reprints : Jae Seung Bang

Department of Neurosurgery, Seoul National University Bundang Hospital, Seoul National University College of Medicine, 82 Gumi-ro 173beon-gil, Bundang-gu, Seongnam 13620 , Korea

Tel : +82-31-787-7169, Fax : +82-31-787-4059, E-mail : nsbang@snubh.org, ORCID : https://orcid.org/0000-0001-9543-8758

Si Un Lee

Department of Neurosurgery, Seoul National University Bundang Hospital, Seoul National University College of Medicine, 82 Gumi-ro 173beon-gil, Bundang-gu, Seongnam 13620 , Korea

Tel : +82-31-787-7169, Fax : +82-31-787-4059, E-mail : nsmidget@gmail.com, ORCID : https://orcid.org/0000-0001-5788-2014

This is an Open Access article distributed under the terms of the Creative Commons Attribution Non-Commercial License (http://creativecommons.org/licenses/by-nc/4.0) which permits unrestricted non-commercial use, distribution, and reproduction in any medium, provided the original work is properly cited. 


\section{INTRODUCTION}

Fusiform intracranial aneurysms (IAs) account for 3 to $13 \%$ of all IAs, with the vertebrobasilar system being their most common site of occurrence. Fusiform middle cerebral artery (MCA) aneurysms occur most frequently in the anterior circulation, followed by the internal carotid artery and the anterior cerebral artery ${ }^{2,8,32,36)}$. The pathogenesis of fusiform IAs is known to be dissection, atherosclerosis, or connective tissue disease, and the clinical course of the disease has been reported to be related to its pathogenesis ${ }^{30)}$. However, the pathogenesis and clinical course of fusiform MCA aneurysms (FMCAAs) are seldom known, although the occurrence of

Table 1. Literature containing FMCAA cases published from 1980 to 2018

\begin{tabular}{|c|c|}
\hline Study & Number of FMCAA \\
\hline Cohen et al..$^{5)}(1980)$ & 1 \\
\hline Borzone et al. ${ }^{4)}(1993)$ & 2 \\
\hline Horowitz et al. ${ }^{13)}$ (1994) & 1 \\
\hline Anson et al. ${ }^{3)}$ (1996) & 11 \\
\hline Drake and Peerless ${ }^{8)}$ (1997) & 7 \\
\hline Al-Yamany and Ross ${ }^{2)}$ (1998) & 1 \\
\hline Nakatomi et al. ${ }^{26)}(2000)$ & 5 \\
\hline Niikawa et al. ${ }^{28)}(2002)$ & 1 \\
\hline Horie et al. ${ }^{12)}(2003)$ & 3 \\
\hline Pumar et al. ${ }^{311}$ (2008) & 1 \\
\hline Park et al..$^{30)}(2008)$ & 4 \\
\hline Hanel and Spetzler ${ }^{111}(2008)$ & 1 \\
\hline Hrbác et al. ${ }^{14)}$ (2009) & 1 \\
\hline Seo et al. ${ }^{33)}(2009)$ & 4 \\
\hline Jeong et al. ${ }^{15)}(2010)$ & 1 \\
\hline Nakajima et al. ${ }^{25)}$ (2012) & 3 \\
\hline Kalani et al. ${ }^{16)}$ (2013) & 12 \\
\hline Devulapalli et al.") (2013) & 1 \\
\hline Zhu et al. ${ }^{40)}$ (2013) & 3 \\
\hline Monteith et al. ${ }^{23)}$ (2014) & 7 \\
\hline Mrak et al. ${ }^{24)}$ (2016) & 1 \\
\hline Durst et al. ${ }^{9)}(2016)$ & 1 \\
\hline Tayebi Meybodi et al. ${ }^{34)}$ (2017) & 20 \\
\hline Alturki et al.' (2018) & 2 \\
\hline Xu et al. ${ }^{38)}$ (2018) & 18 \\
\hline
\end{tabular}

FMCAA : fusiform middle cerebral artery aneurysm fusiform aneurysms in the vertebrobasilar system is relatively well known ${ }^{10,18,22,27,29,39)}$. Especially, because of the low incidence of FMCAAs, there were few reports on their clinical course according to their location, size, and configuration, though patients with FMCAAs may present with various symptoms such as intracranial hemorrhage, cerebral ischemia, seizure, and mass effects depending on the location, size, and configuration ${ }^{40)}$.

We analyzed the angiographic features and clinical course, including treatment outcomes and the natural course, of FMCAAs according to their location, size, and configuration.

Table 2. Characteristics of all the patients

\begin{tabular}{|c|c|}
\hline Characteristic & Value \\
\hline Age & $48.2 \pm 15.8$ \\
\hline Male & $72(49.7)$ \\
\hline Presentation & 145 \\
\hline Hemorrhage & $32(22.1)$ \\
\hline Ischemia & $35(24.1)$ \\
\hline Seizure & $6(4.1)$ \\
\hline Mass effect & $16(11.0)$ \\
\hline Incidental finding & $56(38.6)$ \\
\hline Size & $144^{*}$ \\
\hline Small & $18(12.5)$ \\
\hline Large & $53(36.8)$ \\
\hline Giant & $73(50.7)$ \\
\hline Location & $127^{\dagger}$ \\
\hline $1 \mathrm{a}$ & $30(23.6)$ \\
\hline $1 b$ & $26(20.5)$ \\
\hline $2 \mathrm{a}$ & $7(5.5)$ \\
\hline $2 b$ & $12(9.4)$ \\
\hline $3 a$ & 34 (26.8) \\
\hline $3 b$ & $18(14.2)$ \\
\hline Configuration & $122^{\ddagger}$ \\
\hline 1 & $1(0.8)$ \\
\hline 2 & $61(50.0)$ \\
\hline 3 & $60(49.2)$ \\
\hline
\end{tabular}

Values are presented as mean \pm standard deviation or number (\%). ${ }^{*}$ The exact size could not be determined in 1 FMCAA. ${ }^{\dagger}$ The exact location type could not be identified in 18 FMCAAs. ${ }^{\text {T}}$ The exact configuration type could not be determined in 23 FMCAAs. FMCAA : fusiform middle cerebral artery aneurysm 


\section{MATERIALS AND METHODS}

\section{Study population}

This study was approved by the Institutional Review Boards of Seoul National University Bundang Hospital (B-1805/466110). We reviewed the literature on adult FMCAA cases published from 1980 to 2018, and extracted only those documents from which the location, size, and shape could be identified. Finally, 112 FMCAA cases from 25 papers were included in this study (Table 1). In addition, we retrospectively analyzed adult patients diagnosed with FMCAAs who visited our hospital between 2003 and 2017. A total of 33 patients, 16 patients who had not undergone surgery and 17 patients who had undergone surgery, were included in this study. Accordingly, a total of 145 adult FMCAA cases were registered in this study to analyze their clinical and angiographic features according

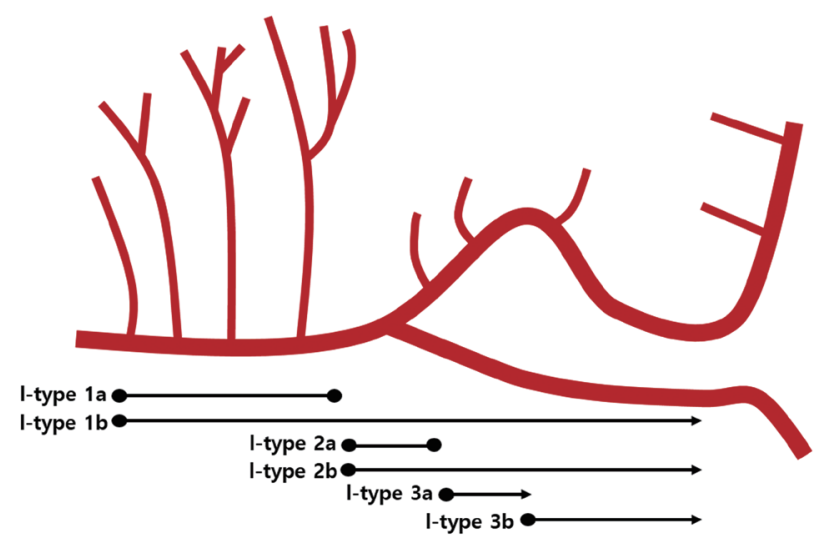

Fig. 1. Classification according to location of FMCAAs. I-type 1a, located only at prebifurcation; I- type $1 \mathrm{~b}$, beginning from prebifurcation to postbifurcation; I-type $2 \mathrm{a}$, located only at bifurcation; I-type $2 \mathrm{~b}$, beginning from bifurcation to postpostbifurcation; l-type 3a, beginning from postbifurcation and mainly located on M2; l-type 3b, mainly located after M3 or M3. FMCAA : fusiform middle cerebral artery aneurysm. to their location, size, and configuration, and natural history was observed in 16 patients who had not undergone surgery. The baseline characteristics are presented in Table 2 .

\section{Location and size}

The anatomical location of FMCAAs is an important determinant of the treatment modality, and it is generally classified as prebifurcation, bifurcation, and postbifurcation ${ }^{17,34)}$. We divided the existing classification into more details based on the actual FMCAA location according to the following criteria : location type (l-type) la (located only at the prebifurcation), l- type $1 b$ (beginning from the prebifurcation to postbifurcation), l-type 2a (located only at the bifurcation), l-type 2b (beginning from the bifurcation to postpostbifurcation), l-type 3a (beginning from postbifurcation and mainly located on M2), and l-type 3b (mainly located after M3 or M3) (Fig. 1).

Based on the size, the FMCAAs were classified as small $(<10$ $\mathrm{mm}$ in diameter), large (10-24 $\mathrm{mm}$ in diameter), and giant (diameter $\geq 25 \mathrm{~mm}$ ) according to the conventional classifica$\operatorname{tion}^{6,40)}$

\section{Configuration}

Mizutani and Kojima ${ }^{22)}$ classified fusiform IAs according to angiographic and histopathological features as follows. Type 1 is a "classic dissecting aneurysm" showing a typical pseudolumen with packed fresh thrombus, and the portion of the pseudolumen corresponds to irregular stenosis on angiography. Angiography of such arterial dissections frequently shows irregular stenosis without aneurysmal dilatation (Fig. 2A). Type 2 is "segmental ectasia" appearing as luminal dilatation with distended or fragmented internal elastic lamina and thickened intima; thrombus formation does not occur in type 2 aneurysms. Angiography of this type shows fusiform aneurysm with smooth contour (Fig. 2B). Finally, type 3, "dolicho-
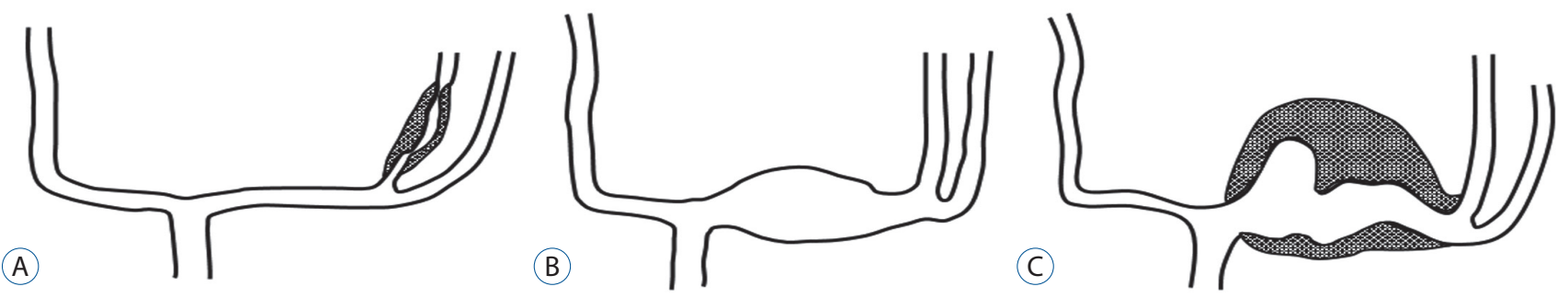

Fig. 2. Classification according to configuration of FMCAAs. A : c-type 1, classic dissecting aneurysm. B : c-type 2, segmental ectasia. C : c-type 3, dolichoectatic dissecting aneurysm. FMCAA : fusiform middle cerebral artery aneurysm. 
ectatic dissecting aneurysm", is characterized by tortuous fusiform appearance with irregular contrast due to luminal thrombus (Fig. 2C) ${ }^{22)}$. We also classified the aneurysms based on Mizutani's classification and named them as configuration type (c-type) 1, c-type 2, and c-type 3 to distinguish them from location types.

\section{Clinical features}

Clinical features were reviewed and analyzed for initial presentations, treatment outcomes, and natural history. The initial presentation was mainly an intracranial hemorrhage, cerebral ischemia, seizure, mass effect, or incidental finding. The mass effect was defined as the presence of a symptomatic lesion with brain shift, sulcal effacement, or cerebral edema on computed tomography or magnetic resonance imaging ${ }^{21)}$. The treatment outcome was evaluated based on the modified Rankin Score (mRS) and classified as mild (0-1), moderate $(2-3)$, and severe (4-5). We also analyzed whether the mRS deteriorated after surgery compared to before.
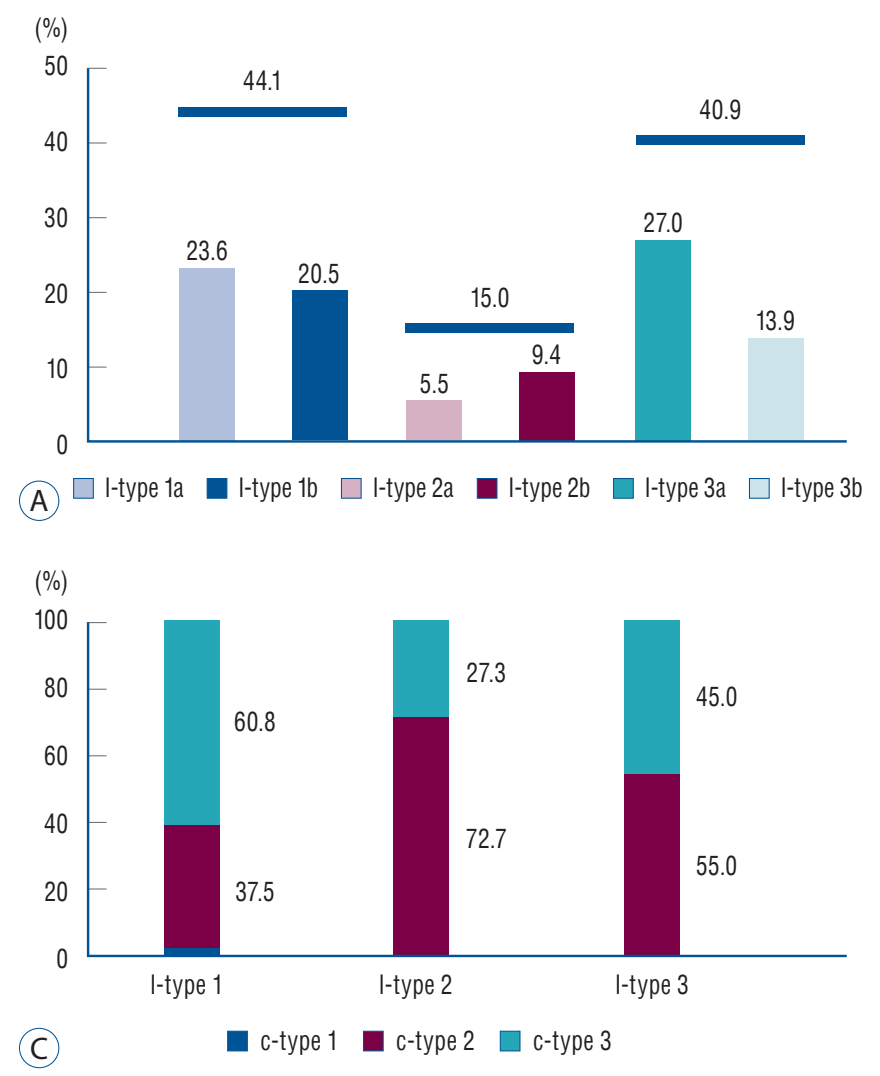

Natural history was observed in 16 patients who did not undergo surgery, and risk factor evaluation was performed in patients whose aneurysm size increased during follow-up. We performed statistical analysis using the SPSS statistical software (version 22; IBM Corp., Armonk, NY, USA). Categorical variables are presented as numbers and percentages. Continuous data are shown as mean \pm standard deviation. The Fisher exact test and Manne-Whitney $U$ test were used to evaluate the risk factors for the increased size of FMCAAs. $p$-values less than 0.05 were considered to indicate statistical significance.

\section{RESULTS}

\section{Characteristics according to location}

In total, $44.1 \%$ of the FMCAAs (1-type 1a, 23.6\%; 1-type 1b, $20.5 \%$ ) occurred at the prebifurcation (l-type 1) and $15.0 \%$ $(2 \mathrm{a}, 5.5 \% ; 2 \mathrm{~b}, 9.4 \%)$ and $40.9 \%(3 \mathrm{a}, 27.0 \% ; 3 \mathrm{~b}, 13.9 \%)$ at the bifurcation (1-type 2) and postbifurcation (1-type 3), respec-
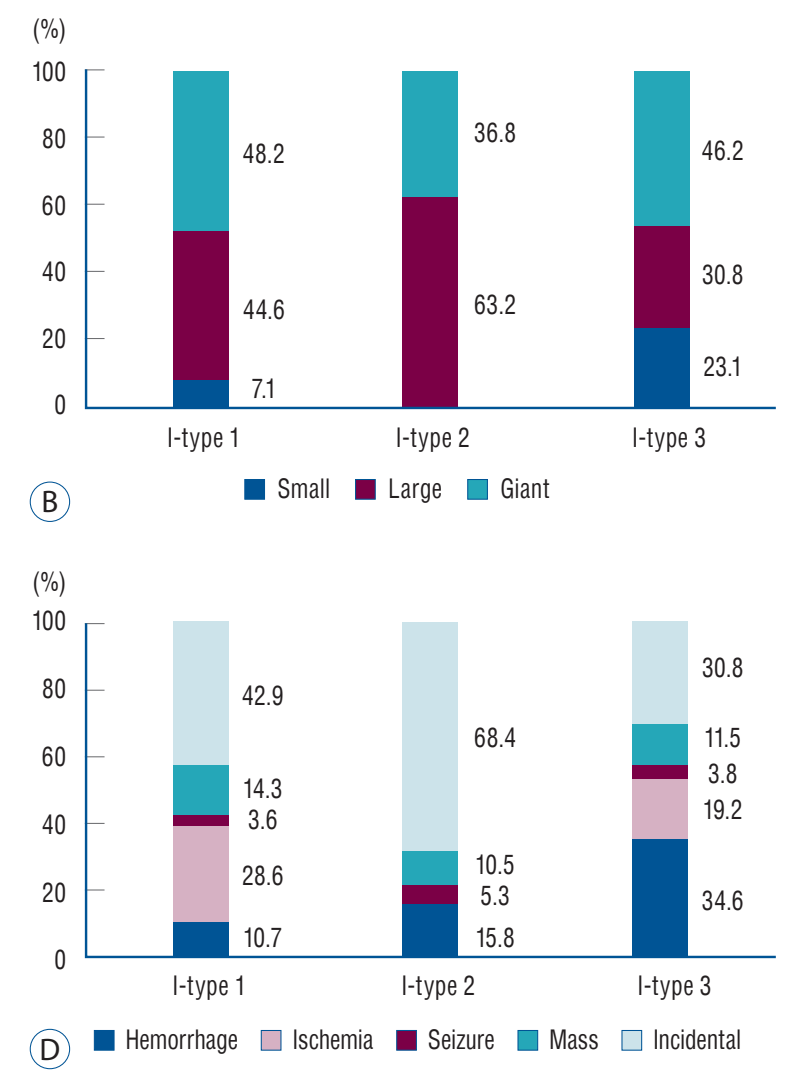

Fig. 3. Characteristics according to location of FMCAAs. A : Frequency of occurrence of FMCAAs according to location. B : Distribution ratio of size of FMCAAs by location. C : Distribution ratio of configuration of FMCAAs by location. D : Clinical presentation according to location of FMCAAs. FMCAA : fusiform middle cerebral artery aneurysm. 
tively (Fig. 3A). An analysis of the size of FMCAAs according to location revealed that the giant aneurysms accounted for $48.2 \%, 36.8 \%$, and $46.2 \%$ of l-type 1, l-type 2 , and l-type 3, respectively. Furthermore, large aneurysms accounted for $44.6 \%, 63.2 \%$, and $30.8 \%$, and small aneurysms, $7.1 \%, 0 \%$, and $23.1 \%$ of l-type 1, 1-type 2, and 1-type 3, respectively (Fig. 3B). An analysis of the configuration of FMCAAs according to location revealed that $37.5 \%$ and $60.8 \%$ of l-type 1 were segmental ectasia type (c-type 2) and dolichoectatic dissecting type (c-type 3), respectively. Moreover, they accounted for $72.7 \%$ and $27.3 \%$, respectively, in l-type 2 and $55.0 \%$ and $45.0 \%$, respectively, in l-type 3 (Fig. 3C). An analysis of the initial symptoms depending on location revealed that the most common symptom in l-type 1 was ischemia (28.6\%) and the second most common symptom was the mass effect (14.3\%). The l-type 2 was more frequently found incidentally (68.4\%) compared to other l-types and in case of 1-type 3, hemorrhagic presentation (34.6\%) was the most common, followed by ischemia (19.2\%) (Fig. 3D).
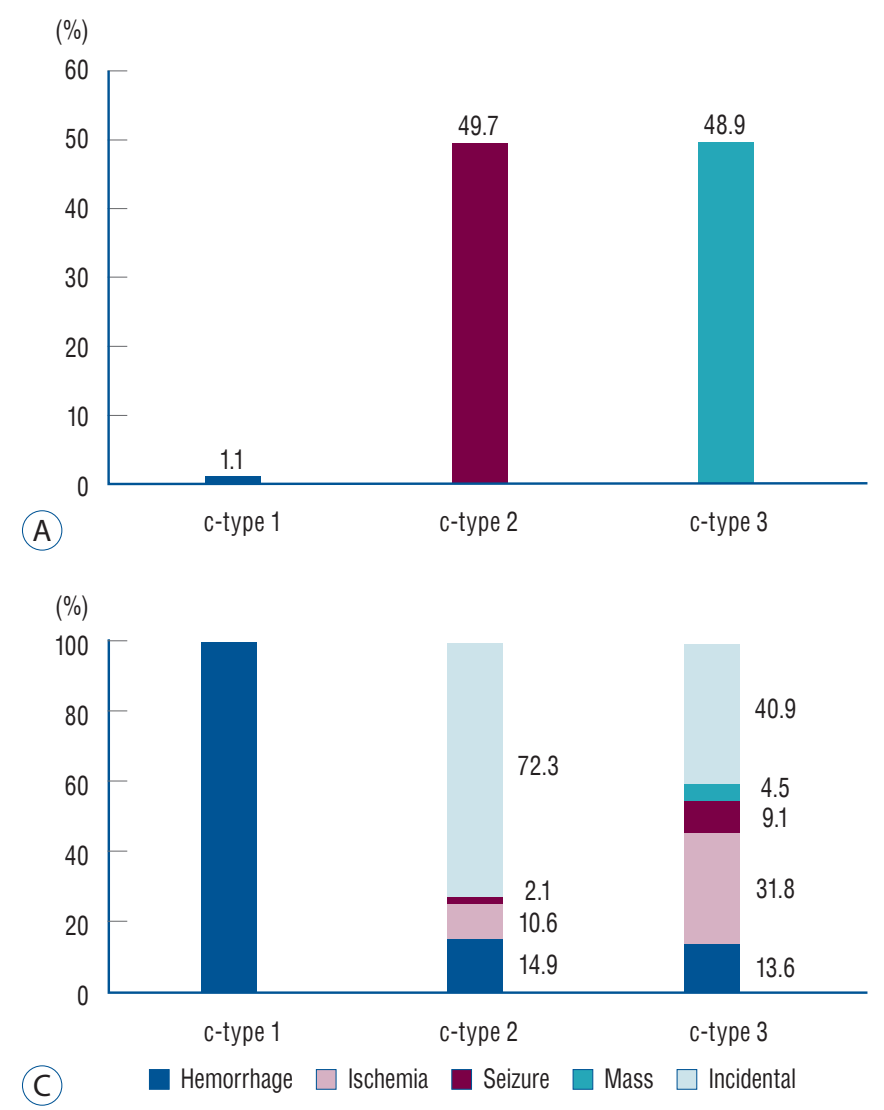

\section{Characteristics according to configuration}

According to the analysis based on configuration, the ratio of c-type 2 and c-type 3 was similar at 49.7\% and 48.9\% (Fig. 4A). Regarding the size according to the configuration, the giant aneurysms accounted for largest proportion, 60.0\%, in c-type 3, followed by large aneurysms (30.0\%). On the other hand, the large aneurysms accounted for $68.9 \%$ of c-type 2 , followed by small aneurysms, which accounted for 19.7\% (Fig. 4B). Regarding the initial symptoms according to configuration, the rate of ischemia in c-type 3 was higher at $31.8 \%$, while that of hemorrhage was lower at $13.6 \%$. In contrast, the rate of hemorrhage in c-type 2 was higher at $14.9 \%$, while that of ischemia was lower at $10.6 \%$ (Fig. 4C).

\section{Characteristics according to size}

While $61.1 \%$ of small aneurysms were discovered incidentally, only $28.8 \%$ of giant aneurysms were discovered incidentally. Moreover, only $11.1 \%$ of small aneurysms were found to be hemorrhagic, while $18.9 \%$ and $26.0 \%$ of large and giant an-
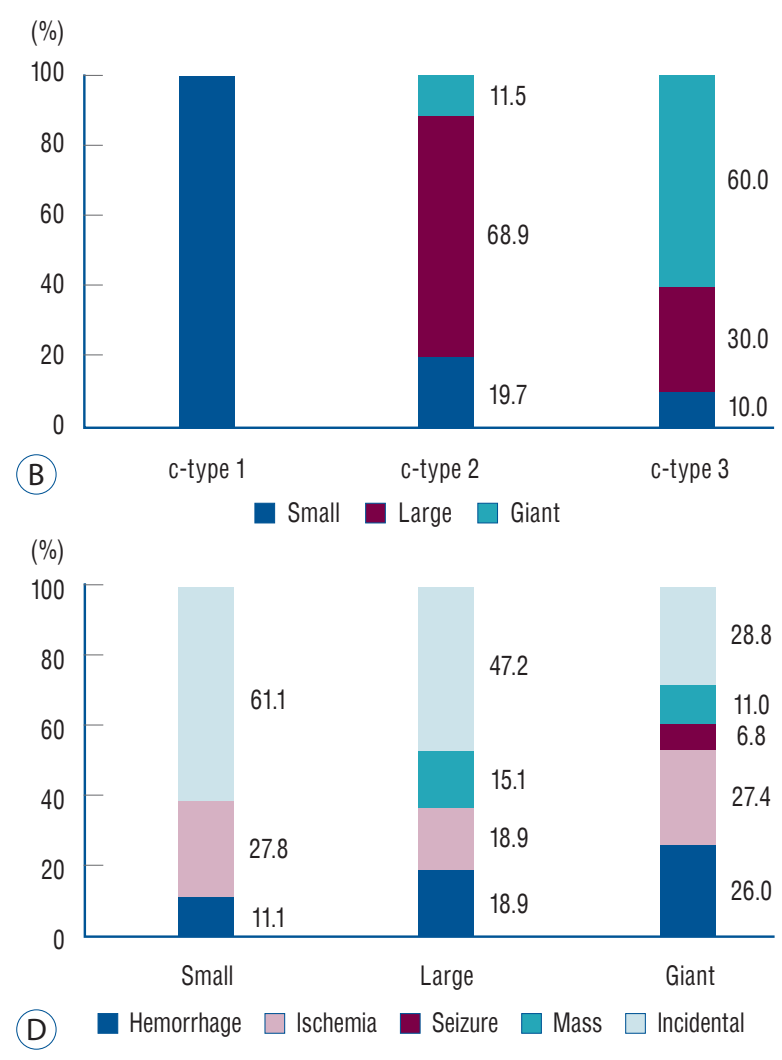

Fig. 4. Characteristics according to location and size of FMCAAs. A : Frequency of occurrence of FMCAAs according to configuration. B : Distribution ratio of size of FMCAAs by configuration. $C$ : Clinical presentation according to configuration of FMCAAs. D : Clinical presentation according to size of FMCAAs. FMCAA : fusiform middle cerebral artery aneurysm. 
eurysms were hemorrhagic, respectively (Fig. 4D).

\section{Natural course of FMCAAs}

We observed a mean of $82.3 \pm 40.3$ months for 16 aneurysms in 16 patients who had not undergone surgery; two aneurysms (12.5\%) were giant aneurysms and 10 (62.5\%) were large aneurysms. Of the 16 FMCAAs, four increased in size and one decreased in size during the observation period and the average period of increase in size was $106.1 \pm 48.9$ months (11.8129.5 months). Of the four FMCAAs that increased in size, two, which were c-type 3 , showed arterial occlusion due to enlarged thrombus. One of them was l-type $2 \mathrm{a}$ and acute infarction was found in the temporal lobe because of one branch artery occlusion. The patient showed mild dysphasia, but eventually this improved (case 1, Fig. 5). The other one was 1type 3 a that showed no symptoms despite the distal branch occlusion (case 2, Fig. 6). There has been no significant change in size since the increase was initially observed, as well as no rupture in any case. The classification of the four enlarged aneurysms by location and configuration is shown in Table 3.
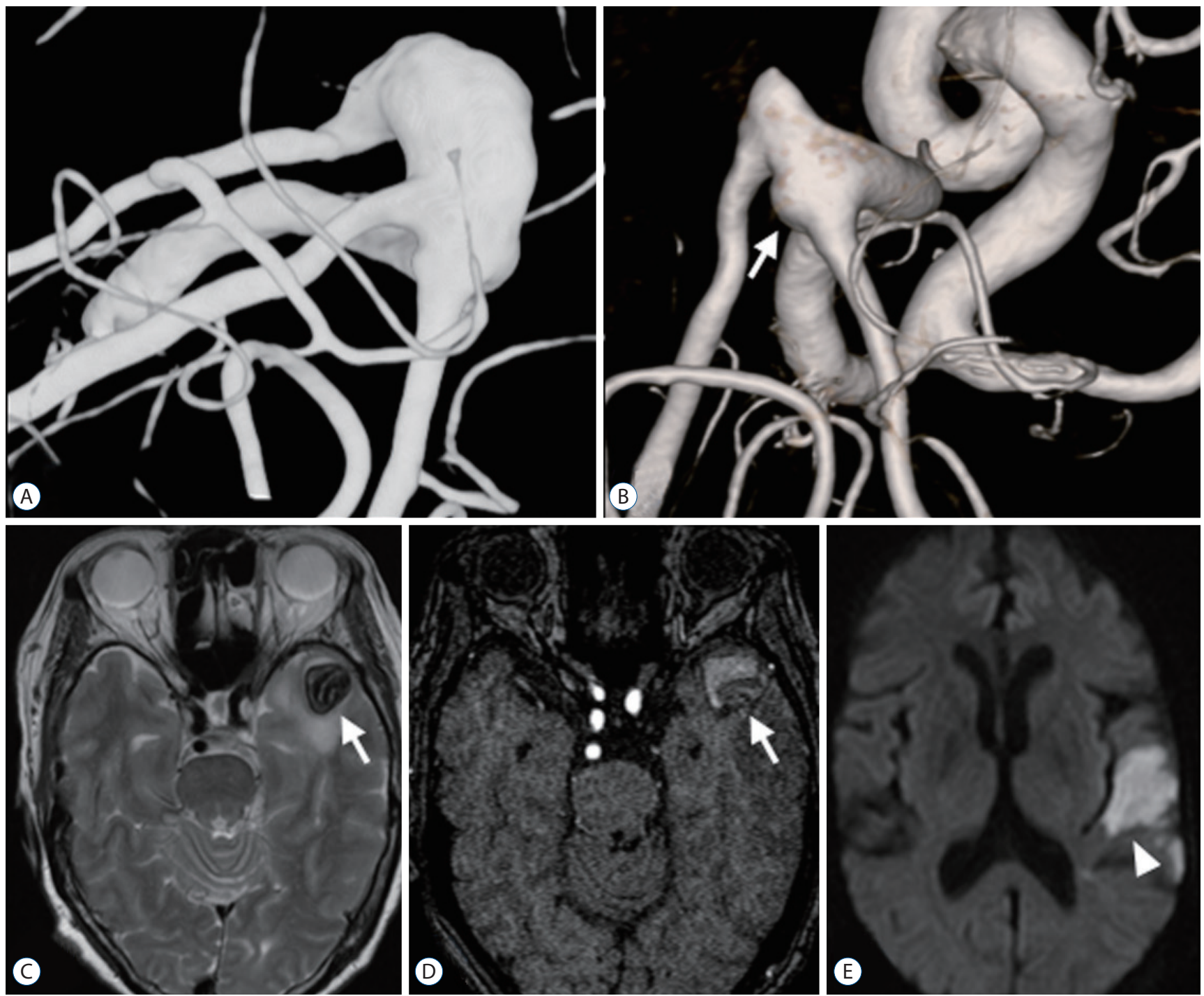

Fig. 5. Case 1, 67-year-old woman. A and C: MRI and TFCA revealed that the FMCAA (white arrow) was classified as I-type 2a and c-type 3, and the maximum diameter was $19 \mathrm{~mm}$. B : After 83 months, the occlusion of middle branch of postbifurcation MCA (white arrow) was found on TFCA. D and E : MRI showed the increased size of thrombosed aneurysm (white arrow) to $22 \mathrm{~mm}$ and detected the acute infarction (arrowhead) in the temporal lobe. MRI : magnetic resonance imaging, TFCA : transfemoral carotid angiography, FMCAA : fusiform middle cerebral artery aneurysm, MCA : middle cerebral artery. 
There were no significant predictors of aneurysm enlargement when analyzed by sex, age, underlying disease, size, location, and configuration.

\section{Treatment outcomes of FMCAAs}

Among the 121 FMCAAs treated, the difference between before and after treatment could be confirmed in $104 \mathrm{FM}-$ CAAs. Of the 104 FMCAAs, 86 (82.7\%) were treated surgically, $12(11.5 \%)$ were treated with endovascular procedures, and six FMCAAs (5.8\%) with combined treatment. Overall, 14 $(13.5 \%)$ cases were aggravated than before surgery. Among them, the cases of $9.7 \%$ of patients with large FMCAAs and $16.9 \%$ of patients with giant FMCAAs deteriorated compared with the preoperative status. Comparing by location, exacerbations were observed in $45.5 \%$ of l-type la and $25.0 \%$ of l-type $1 \mathrm{~b}$, but the patients with FMCAAs at other locations did not show deterioration. Additionally, comparing by shape, deterioration was observed in $8.8 \%$ of patients with c-type 2 , and $19.6 \%$ patients with c-type 3 (Table 4 ).

\section{Representative cases}

\section{Case 1}

A thrombosed fusiform aneurysm located in the left MCA
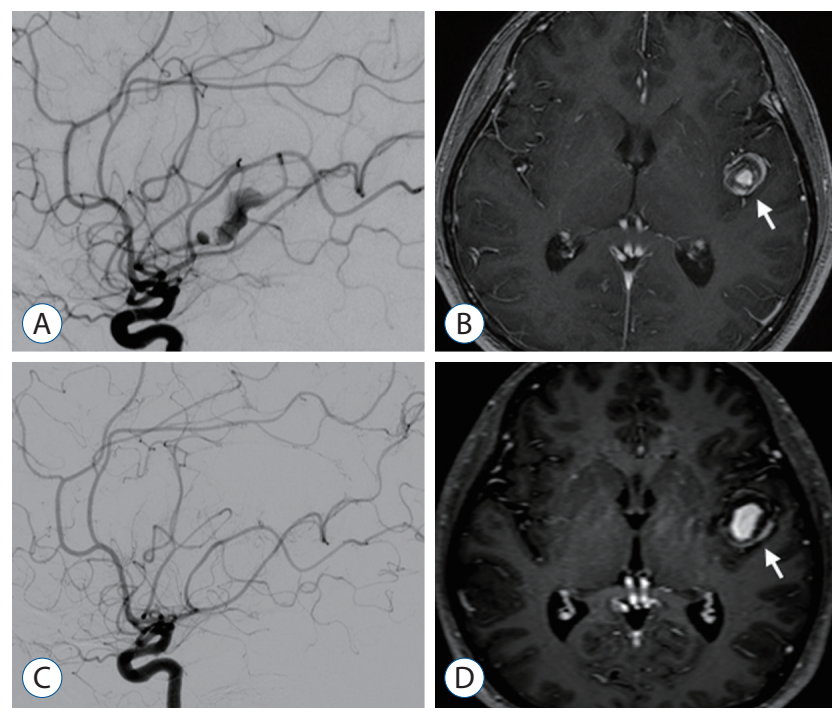

Fig. 6. Case 2, 50-year-old woman. A and B : A thrombosed fusiform aneurysm (white arrow) with maximum diameter of $18 \mathrm{~mm}$ was diagnosed and was classified as I-type 3a and c-type 3. C and D : One year later, the maximum diameter increased to $25 \mathrm{~mm}$ and distal artery occlusion was observed because of increased size of thrombus (white arrow). trifurcation was incidentally found in a 67-year-old woman. MRI and TFCA revealed that the FMCAA was classified as l-type 2a and c-type 3, and the maximum diameter was 19 $\mathrm{mm}$. Surgery was recommended, but the patient refused and was treated conservatively. After 83 months, she was admitted to the emergency room with mild dysphasia, and acute infarction was diagnosed in the temporal lobe caused by branch artery occlusion. The maximum diameter of the FMCAA was increased to $22 \mathrm{~mm}$. Conservative treatment was maintained and symptoms completely resolved. Thereafter, antiplatelets were administered and there was no further increase in size (Fig. 5).

Table 3. Clinical outcome of patients in the observation group

\begin{tabular}{|c|c|c|c|c|}
\hline Characteristic & No change & Increase & Decrease & $p$-value \\
\hline Number of patients & 11 & 4 & 1 & \\
\hline Sex & & & & 0.48 \\
\hline Male & 4 & 1 & 1 & \\
\hline Female & 7 & 3 & 0 & \\
\hline Age & $54.3 \pm 16.0$ & $61.1 \pm 8.1$ & 45.7 & 0.38 \\
\hline Hypertension & 5 & 4 & 0 & 0.09 \\
\hline Diabetes mellitus & 1 & 1 & 0 & 0.45 \\
\hline Smoking & 1 & 1 & 1 & 1.00 \\
\hline $\begin{array}{l}\text { Follow-up duration } \\
\text { (months) }\end{array}$ & $80.1 \pm 43.1$ & $106.1 \pm 48.9$ & 21.7 & \\
\hline \multicolumn{5}{|l|}{ Size } \\
\hline Small & 4 & 0 & 0 & 0.52 \\
\hline Large & 6 & 3 & 1 & 1.00 \\
\hline Giant & 1 & 1 & 0 & 1.00 \\
\hline \multicolumn{5}{|l|}{ Location } \\
\hline $1 a$ & 2 & 1 & 0 & 1.00 \\
\hline $1 b$ & 6 & 0 & 0 & 0.23 \\
\hline $2 a$ & 0 & 2 & 0 & 0.05 \\
\hline $2 b$ & 1 & 0 & 0 & 1.00 \\
\hline $3 a$ & 2 & 1 & 0 & 1.00 \\
\hline $3 b$ & 0 & 0 & 1 & NA \\
\hline \multicolumn{5}{|l|}{ Configuration } \\
\hline 1 & 0 & 0 & 0 & NA \\
\hline 2 & 10 & 2 & 0 & 0.15 \\
\hline 3 & 1 & 2 & 1 & 0.15 \\
\hline
\end{tabular}

Values are presented as mean \pm standard deviation or number. NA : not available 
Table 4. Clinical outcome of treatments

\begin{tabular}{|c|c|c|}
\hline Characteristic & Aggravation & No aggravation \\
\hline Total & $14(13.5)$ & $90(86.5)$ \\
\hline \multicolumn{3}{|l|}{ Size } \\
\hline Small & $0(0)$ & $8(100)$ \\
\hline Large & $3(9.7)$ & $28(90.3)$ \\
\hline Giant & $11(16.9)$ & $54(83.1)$ \\
\hline \multicolumn{3}{|l|}{ Location* } \\
\hline $1 a$ & $10(45.5)$ & $12(54.5)$ \\
\hline $1 b$ & $4(25.0)$ & $12(75.0)$ \\
\hline $2 a$ & $0(0)$ & $4(100)$ \\
\hline $2 b$ & $0(0)$ & $9(100)$ \\
\hline 3а & $0(0)$ & $30(100)$ \\
\hline $3 b$ & $0(0)$ & $10(100)$ \\
\hline \multicolumn{3}{|l|}{ Configuration $^{\dagger}$} \\
\hline 1 & $0(0)$ & $0(0)$ \\
\hline 2 & $3(8.8)$ & $31(91.2)$ \\
\hline 3 & $11(19.6)$ & $45(80.4)$ \\
\hline \multicolumn{3}{|l|}{ Treatments } \\
\hline Reconstructive clipping & $2(15.4)$ & $11(84.6)$ \\
\hline $\begin{array}{l}\text { Bypass with PO, DO, } \\
\text { trapping, or excision }\end{array}$ & $10(13.7)$ & $63(86.3)$ \\
\hline Stenting & $0(0)$ & $1(100)$ \\
\hline $\begin{array}{l}\text { Stent assisted coil } \\
\text { embolization }\end{array}$ & $0(0)$ & $1(100)$ \\
\hline $\begin{array}{l}\text { Bypass with endovascular } \\
\text { trapping }\end{array}$ & $0(0)$ & $6(100)$ \\
\hline Pipeline embolization & $2(20)$ & $8(80)$ \\
\hline
\end{tabular}

Values are presented as number (\%). *The exact location type could not be identified in 13 FMCAAs. ${ }^{\dagger}$ The exact configuration type could not be determined in 14 FMCAAs. PO : proximal occlusion, DO : distal occlusion, FMCAA : fusiform middle cerebral artery aneurysm

\section{Case 2}

A thrombosed fusiform aneurysm in the left M2 artery was incidentally found in a 50-year-old woman. The FMCAA was classified as l-type $3 \mathrm{a}$ and c-type 3 , and the maximum diameter was $18 \mathrm{~mm}$. Surgery was recommended, but the patient refused and she was treated conservatively. One year later, the maximum diameter increased to $25 \mathrm{~mm}$ and distal artery occlusion was observed. Fortunately, there were no neurological symptoms, and there was no change afterwards (Fig. 6).

\section{Case 3}

A 72-year-old man with bladder cancer was found to have
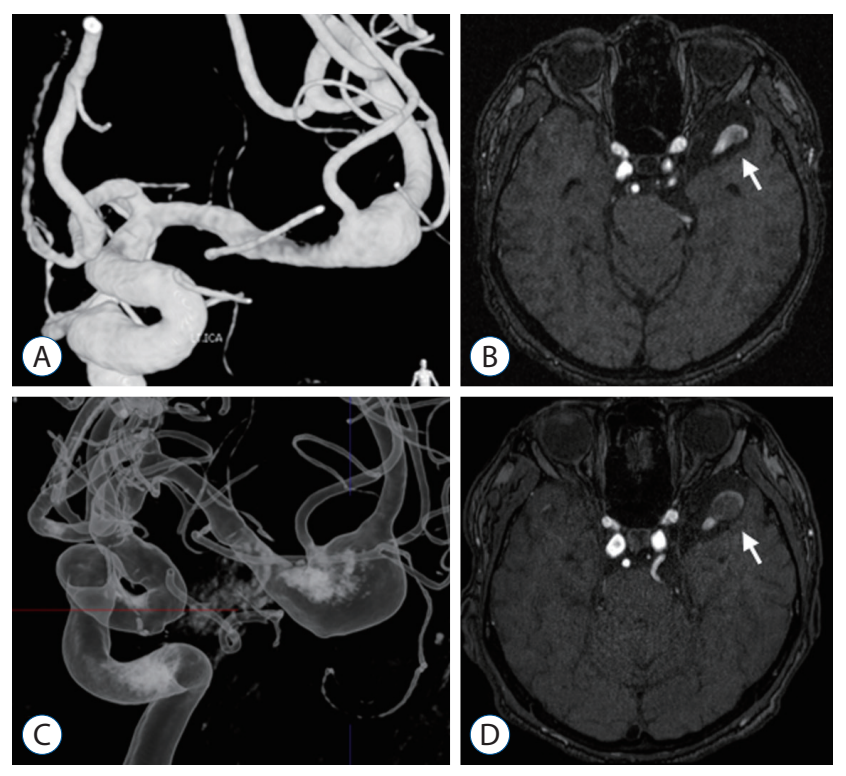

Fig. 7. Case 3, 72-year-old man. A and B : FMCAA, classified as l-type 2a and c-type 2, was detected on TFCA and MRI (white arrow), and maximum dimeter was $15 \mathrm{~mm}$. $C$ and $D$ : After 49 months, the maximum diameter increased to $18 \mathrm{~mm}$ (white arrow), but there was no rupture of aneurysm for 8 years until recently. FMCAA : fusiform middle cerebral artery aneurysm, TFCA : transfemoral carotid angiography, MRI : magnetic resonance imaging.

fusiform aneurysm in the left MCA bifurcation in tests conducted because of a headache. On MRI and TFCA, l-type 2a and c-type 2 were revealed, and maximum dimeter was 15 $\mathrm{mm}$. Conservative treatment was decided, considering old age and underlying diseases. In the examination conducted 49 months later, the maximum diameter increased to $18 \mathrm{~mm}$, but there was no rupture of aneurysm for 8 years until recently (Fig. 7).

\section{DISCUSSION}

According to the present study, c-type 3 was more common with ischemic symptoms (31.8\%) than hemorrhage (13.6\%), while $40.9 \%$ of these FMCAAs were found accidentally. In contrast, c-type 2 was more common with hemorrhagic symptoms (14.9\%) than ischemic symptom (10.6\%), and $72.3 \%$ were discovered by accident. A previous meta-analysis for the natural history of vertebrobasilar dolichoectatic and fusiform aneurysms demonstrated that patients with fusiform aneurysms, which means c-type 2 in this study, had higher rupture rates than those with dolichoectatic aneurysms, 
which means c-type 3 in this study, and patients with dolichoectatic aneurysms had higher ischemic stroke rates than those with fusiform aneurysms, but this did not reach statistical significance ${ }^{27}$. Furthermore, Mizutani and Kojima ${ }^{22)}$ demonstrated that segmental ectasia type of fusiform aneurysm was usually asymptomatic and was incidentally diagnosed. In this study, c-type 3 was assumed to have more symptoms than ctype 2 because $60.0 \%$ of c-type 3 aneurysms were giant aneurysms in contrast to c-type 2 in which only $11.5 \%$ were giant aneurysm, as well as having intramural or intraluminal hematoma. In addition, the fact that $60.8 \%$ of l-type 1 , in which most lenticulostriate arteries (LSA) are located ${ }^{19}$, were c-type 3 , can be a causative factor for ischemic symptoms.

Analyzing according to location, l-type 1 was found most frequently (44.1\%) and the ratio of large aneurysm (44.6\%) and giant aneurysm (48.2\%) was higher in l-type 1 compared with that in l-type 3 . The reason can be assumed as that the pathogenesis of FMCAAs was known as arterial dissection ${ }^{6,30)}$, and it has been reported that the shear stress that causes the dissection increases with the proximity of the region ${ }^{35,37}$. However, the reason why l-type 3 was reported more frequently than l-type 2 despite of lower proximity of the region is supposed that the MCA bifurcation is more susceptible site to saccular aneurysm than fusiform aneurysm. Analyzing the location-specific symptoms, $28.6 \%$ of l-type 1 cases showed ischemic symptoms, while $68.4 \%$ of l-type 2 were found by accident and $34.6 \%$ of l-type 3 were found as hemorrhage. The reason for this is that c-type 3 , which can cause ischemia more frequently, was the most common (60.8\%) in l-type 1, and c-type 2 , in which hemorrhage is a more frequent symptom, was the most common (55.0\%) in l-type 3. In the case of 1-type 2, the proportion of giant aneurysms was relatively low (36.8\%) and l-type 2 aneurysms were located in the border of the anterior and posterior compartments of the sylvian cistern where the cistern is wider ${ }^{20)}$. This may explain why $68.2 \%$ of l-type 2 aneurysms were found incidentally without symptoms.

When analyzing the articles included in this study, l-type of FMCAA is the most important factor in determining the method of treatment. If LSA is involved in l-type 1, reconstructive clipping, proximal occlusion (PO) with bypass or distal occlusion with bypass is considered. If LSA is not involved, trapping with bypass or excision with bypass can be performed. However, if MCA bifurcation is involved, such as in l-type $1 \mathrm{~b}$, a combination bypass should be considered. In case of 1-type 2a, reconstructive clipping can be considered, but l-type $2 \mathrm{~b}$ was treated with trapping with combination bypass or PO with combination bypass. L-type 3 can be considered for trapping with bypass or excision with bypass. However, l-type 3a was treated with PO with bypass in cases located near the insular apex. In addition, endovascular treatment, such as stenting, stent-assisted coil embolization, or pipeline embolization, was performed for l-type 1 or l-type 3. Analyzing the results of the treatment, $13.5 \%$ (14 patients) deteriorated after the treatments, though among the 14 patients in whom there was aggravation after the treatments, nine (64.3\%) were relatively healthy with a mRS score of 0 or 1 before the treatments. In addition, the cases that deteriorated after treatments were all l-type 1 and $36.8 \%$ of l-type 1 cases experienced aggravation after treatments.

In contrast, we observed the natural course of 16 FMCAA cases, and although the giant aneurysm was only included in two cases, there were no cases that ruptured during the observation period. In addition, although there were four cases in which the aneurysm increased in size, they did not increase after a certain period (11.8-129.5 months). Though blood pressure may have been thoroughly controlled after diagnosis of the aneurysm, this result shows that the natural course of the FMCAAs, especially that of c-type 2 , is relatively benign. However, although our patients had improved symptoms, we need to be cautious in determining the observation of c-type 3 without treatments because of the presence of acute infarction caused by arterial occlusion.

Based on the above results, determining the course of treatment for patients with l-type 1 FMCAA with mRS scores of 0 or 1 requires caution because the natural course of FMCAAs is relatively benign compared to the poor results of surgery. However, in the case of conservative treatment without surgery, blood pressure control should be the most basic requirement, and l-type 1 or c-type 3 should be observed closely to prevent the aggravation of ischemic symptoms. In addition, for l-type 3 or c-type 2 , it is also necessary to pay more attention to blood pressure control because of the relatively higher occurrence rate of hemorrhage when observation without surgery is undertaken. However, since FMCAA other than l-type 1 has a relatively good surgical outcome, surgery can be considered for l-type 2 and l-type 3, especially c-type 3, in institutes that can provide expert surgical experience. 


\section{Limitations}

This study has some limitations because of its retrospective design. First, selection bias is one of the most important limitations because this study is based on previous published literature. It is likely that relatively severe cases were reported in case selection, and in therapeutic terms, treatment results were reported mainly in cases with good results. The fact that a natural course without treatment was observed only in 16 cases and that only two giant aneurysms and only four c-type 3 FMCAA were included were also limitations. Accordingly, it can be difficult to accurately understand the natural course of the FMCAAs that induce the symptoms clinically. However, because FMCAA is a rare disease and it is difficult to collect enough cases to study, the results of this study based on the previously reported cases will help to comprehensively identify FMCAA characteristics and predict their natural course.

\section{CONCLUSION}

The study analyzed the clinical characteristics of FMCAAs, which included outcome of treatments and the natural course, according to their location, configuration, and size. In conclusion, in cases of l-type 1 aneurysms, especially when accompanied by c-type 3 , more caution is required in determining the treatment, and careful observation is needed to monitor the occurrence of ischemic symptoms when not treated. On the other hand, in case of l-type 3 and c-type 2, more attention should be paid to blood pressure control to prevent rupture of aneurysms. To obtain more accurate results, a prospective multicenter study is required in the future.

\section{CONFLICTS OF INTEREST}

No potential conflict of interest relevant to this article was reported.

\section{INFORMED CONSENT}

This type of study does not require informed consent.

\section{AUTHOR CONTRIBUTIONS}

\author{
Conceptualization : SUL, JSB \\ Data curation : DS \\ Formal analysis : TK \\ Funding acquisition : JSB \\ Methodology : SPB, HSB \\ Project administration : $\mathrm{CWO}, \mathrm{OK}$ \\ Visualization: YDW, YDK, YL \\ Writing - original draft : DS, SUL \\ Writing - review \& editing : SUL
}

\section{- Acknowledgements}

This study was supported by the Research Funds of the Seoul National University Bundang Hospital.

\section{References}

1. Alturki AY, Schmalz PGR, Ogilvy CS, Thomas AJ : Sequential coilingassisted deployment of flow diverter for treatment of fusiform middle cerebral artery aneurysms. Oper Neurosurg (Hagerstown) 15 : E13E18, 2018

2. Al-Yamany M, Ross IB : Giant fusiform aneurysm of the middle cerebral artery: successful Hunterian ligation without distal bypass. Br J Neurosurg $12: 572-575,1998$

3. Anson JA, Lawton MT, Spetzler RF : Characteristics and surgical treatment of dolichoectatic and fusiform aneurysms. J Neurosurg 84 : 185193, 1996

4. Borzone M, Altomonte M, Baldini M, Silvestro C, Rivano C : Giant fusiform aneurysm in middle cerebral artery branches: a report of two cases and a review of the literature. Acta Neurochir (Wien) 125 : 184-187, 1993

5. Cohen MM, Hemalatha CP, D'Addario RT, Goldman HW : Embolization from a fusiform middle cerebral artery aneurysm. Stroke 11 : 158-161, 1980

6. Day AL, Gaposchkin CG, Yu CJ, Rivet DJ, Dacey RG Jr : Spontaneous fusiform middle cerebral artery aneurysms: characteristics and a proposed mechanism of formation. J Neurosurg 99 : 228-240, 2003

7. Devulapalli KK, Chowdhry SA, Bambakidis NC, Selman W, Hsu DP : Endovascular treatment of fusiform intracranial aneurysms. J Neurointerv Surg 5 : 110-116, 2013

8. Drake CG, Peerless SJ : Giant fusiform intracranial aneurysms: review of 120 patients treated surgically from 1965 to 1992. J Neurosurg 87 : 141-162, 1997

9. Durst CR, Hixson HR, Schmitt P, Gingras JM, Crowley RW : Endovascular treatment of a fusiform aneurysm at the M3-M4 junction of the middle 
cerebral artery using the pipeline embolization device. World Neurosurg 86 : 511.e1-e4, 2016

10. Echiverri HC, Rubino FA, Gupta SR, Gujrati M : Fusiform aneurysm of the vertebrobasilar arterial system. Stroke 20 : 1741-1747, 1989

11. Hanel RA, Spetzler RF : Surgical treatment of complex intracranial aneurysms. Neurosurgery 62 : 1289-1297; discussion 1297-1299, 2008

12. Horie N, Takahashi N, Furuichi S, Mori K, Onizuka M, Tsutsumi K, et al. : Giant fusiform aneurysms in the middle cerebral artery presenting with hemorrhages of different origins. Report of three cases and review of the literature. J Neurosurg 99 : 391-396, 2003

13. Horowitz MB, Yonas $H$, Jungreis $C$, Hung TK : Management of a giant middle cerebral artery fusiform serpentine aneurysm with distal clip application and retrograde thrombosis: case report and review of the literature. Surg Neurol 41 : 221-225, 1994

14. Hrbác $T$, Drábek $P$, Klement $P$, Procházka $V:$ A combined approach to treatment of the dissecting middle cerebral artery fusiform aneurysm. A case report. Interv Neuroradiol 15 : 349-354, 2009

15. Jeong SM, Kang SH, Lee NJ, Lim DJ : Stent-assisted coil embolization for the proximal middle cerebral artery fusiform aneurysm. J Korean Neurosurg Soc 47 : 406-408, 2010

16. Kalani MY, Zabramski JM, Hu YC, Spetzler RF : Extracranial-intracranial bypass and vessel occlusion for the treatment of unclippable giant middle cerebral artery aneurysms. Neurosurgery 72 : 428-435; discussion 435-436, 2013

17. Kivipelto L, Niemelä $M$, Meling $T$, Lehecka $M$, Lehto $H$, Hernesniemi J : Bypass surgery for complex middle cerebral artery aneurysms: impact of the exact location in the MCA tree. J Neurosurg 120 : 398-408, 2014

18. Kobayashi N, Murayama Y, Yuki I, Ishibashi T, Ebara M, Arakawa H, et al. : Natural course of dissecting vertebrobasilar artery aneurysms without stroke. AJNR Am J Neuroradiol 35 : 1371-1375, 2014

19. Marinkovic S, Gibo H, Milisavljevic M, Cetkovic M : Anatomic and clinical correlations of the lenticulostriate arteries. Clin Anat 14 : 190-195, 2001

20. Martin L, Reza D, Jaakko R, Rossana R, Riku K, Mika N, et al. : Surgical management of aneurysms of the middle cerebral artery : Schmidek and Sweet Operative Neurosurgical Techniques, ed 6. Beijing : Elsevier, 2012, pp897-913

21. Miller MT, Pasquale M, Kurek S, White J, Martin P, Bannon K, et al. : Initial head computed tomographic scan characteristics have a linear relationship with initial intracranial pressure after trauma. J Trauma 56 : 967972; discussion 972-973, 2004

22. Mizutani T, Kojima H : Clinicopathological features of non-atherosclerotic cerebral arterial trunk aneurysms. Neuropathology 20 : 91-97, 2000

23. Monteith SJ, Tsimpas A, Dumont AS, Tjoumakaris S, Gonzalez LF, Rosenwasser RH, et al. : Endovascular treatment of fusiform cerebral aneurysms with the Pipeline Embolization Device. J Neurosurg 120 : 945954, 2014

24. Mrak G, Duric KS, Nemir J : Middle cerebral artery fusiform aneurysm presented with stroke and delayed subarachnoid hemorrhage trapping, thrombectomy, and bypass. Surg Neurol Int 7 : S209-S213, 2016
25. Nakajima H, Kamiyama H, Nakamura T, Takizawa K, Tokugawa J, Ohata $\mathrm{K}$ : Direct surgical treatment of giant middle cerebral artery aneurysms using microvascular reconstruction techniques. Neurol Med Chir (Tokyo) $52:$ 56-61, 2012

26. Nakatomi H, Segawa H, Kurata A, Shiokawa Y, Nagata K, Kamiyama $H$, et al. : Clinicopathological study of intracranial fusiform and dolichoectatic aneurysms : insight on the mechanism of growth. Stroke 31 : 896-900, 2000

27. Nasr DM, Flemming KD, Lanzino G, Cloft HJ, Kallmes DF, Murad MH, et al. : Natural history of vertebrobasilar dolichoectatic and fusiform aneurysms: a systematic review and meta-analysis. Cerebrovasc Dis 45 : 68-77, 2018

28. Niikawa S, Yamada J, Sumi Y, Yamakawa H : Dissecting aneurysm of the middle cerebral artery manifesting as subarachnoid hemorrhage and hemorrhagic infarctions--case report. Neurol Med Chir (Tokyo) 42 : 62-66, 2002

29. Park KW, Park JS, Hwang SC, Im SB, Shin WH, Kim BT : Vertebral artery dissection: natural history, clinical features and therapeutic considerations. J Korean Neurosurg Soc 44 : 109-115, 2008

30. Park SH, Yim MB, Lee CY, Kim E, Son El : Intracranial fusiform aneurysms: it's pathogenesis, clinical characteristics and managements. J Korean Neurosurg Soc 44 : 116-123, 2008

31. Pumar JM, Lete I, Pardo MI, Vázquez-Herrero F, Blanco M : LEO stent monotherapy for the endovascular reconstruction of fusiform aneurysms of the middle cerebral artery. AJNR Am J Neuroradiol 29 : 17751776, 2008

32. Selviaridis P, Spiliotopoulos A, Antoniadis C, Kontopoulos V, Foroglou $G$ : Fusiform aneurysm of the posterior cerebral artery: report of two cases. Acta Neurochir (Wien) 144 : 295-299; discussion 299, 2002

33. Seo BR, Kim TS, Joo SP, Lee JM, Jang JW, Lee JK, et al. : Surgical strategies using cerebral revascularization in complex middle cerebral artery aneurysms. Clin Neurol Neurosurg 111 : 670-675, 2009

34. Tayebi Meybodi A, Huang W, Benet A, Kola O, Lawton MT : Bypass surgery for complex middle cerebral artery aneurysms: an algorithmic approach to revascularization. J Neurosurg 127 : 463-479, 2017

35. Tse KM, Chiu P, Lee HP, Ho P : Investigation of hemodynamics in the development of dissecting aneurysm within patient-specific dissecting aneurismal aortas using computational fluid dynamics (CFD) simulations. J Biomech 44 : 827-836, 2011

36. Vega-Basulto SD, Silva-Adán S, Laserda-Gallardo A, Peñones-Montero R, Varela-Hernández A : Giant supratentorial intracranial aneurysms. Analysis of 22 cases. Neurocirugia (Astur) $14:$ 16-24, 2003

37. Weddell JC, Kwack J, Imoukhuede PI, Masud A : Hemodynamic analysis in an idealized artery tree: differences in wall shear stress between Newtonian and non-Newtonian blood models. PLoS One 10 : e0124575, 2015

38. Xu F, Xu B, Huang L, Xiong J, Gu Y, Lawton MT : Surgical treatment of large or giant fusiform middle cerebral artery aneurysms: a case series. World Neurosurg 115 : e252-e262, 2018

39. Yasui T, Komiyama M, Iwai Y, Yamanaka K, Nishikawa M, Morikawa T: Evolution of incidentally-discovered fusiform aneurysms of the vertebro- 
basilar arterial system: neuroimaging features suggesting progressive aneurysm growth. Neurol Med Chir (Tokyo) 41 : 523-527; discussion 528,2001

40. Zhu W, Liu P, Tian Y, Gu Y, Xu B, Chen L, et al. : Complex middle cere- bral artery aneurysms: a new classification based on the angioarchitecture and surgical strategies. Acta Neurochir (Wien) 155 : 1481-1491, 2013 